\title{
CORRESPONDENCE
}

\section{Scientists in the Soviet Union}

SIR - News of oppression crosses my desk daily. It is so commonplace that after a while its impact is almost lost. Like physicians who must become hardened to deal daily with death, human rights workers become somewhat inured to a daily fare of suffering. Nothing breaks down this shell more quickly than a visit to the victims of oppression.

As executive director of the Committee of Concerned Scientists, I went to the Soviet Union recently to investigate at first hand the trying circumstances confronting refusnik and dissident scientists. I found that the familiar litany of persecutions continues unabated. Most scientists who apply for emigration or speak out in defence of human rights are dismissed from their jobs. The regime then does its utmost to ensure their intellectual death by isolating them from their colleagues. In their personal lives too these individuals are plagued by countless harassments. Their homes are searched, their telephones disconnected, their mail intercepted. Scientists who apply to emigrate are routinely refused exit visas on spurious grounds. Anti-semitism is rife in all phases of academic life from admission to universities, to conferral of degrees, to obtaining employment. Those who have fallen from grace are frequently threatened with prosecution on criminal charges. Some are tried and sentenced to prison, labour camp and internal exile. These violations of human rights and scientific freedom are not new developments.

Regrettably we have been hearing about them for some time.

I had learned much about this bleak situation during my four years with the Committee of Concerned Scientists. But I was not prepared for reports of the latest acts of persecution. Harassment has assumed new forms. Even prisoners are subjected to additional vengeful punishment. The health and very lives of prisoners of conscience Sergei Kovalev, Yuri Orlov and Anatoly Shcharansky are in grave jeopardy. Lengthy periods of solitary confinement, reduced rations and inadequate medical attention have taken their toll.

Other ominous trends in the treatment of refusniks and dissidents emerged from my discussions with leaders of these communities. First and most distressing is the wave of trials of scientists. Never before have so many activist scientists been threatened with lengthy sentences at one time. In Kiev Vladimir Kislik was sentenced to three years in a labour camp. Several years ago authorities had sought to imprison him for "compromising secrets" in an article published in an international journal. Yet this research had been officially cleared for publication some five years earlier. When confronted with a flood of protests from Kislik's Western colleagues pointing to the absurdity of this charge, the authorities backed off. In June, however, they achieved their goal through a contrived criminal charge. Computer scientist Viktor Brailovsky, a leader of the Moscow Sunday Scientific Seminar since its inception nine years ago, has been sentenced to five years of internal exile for advocating the right to emigrate, deemed defamatory to the Soviet state. In Leningrad, refusnik mathematician Yevgeny Lein will also soon face trial. Interestingly, Kislik, Brailovsky and Lein all played key roles in organizing seminars designed to maintain the scientific skills of refusnik scientists.

The attempt by the Soviet authorities to close down these unofficial seminars is another cause for alarm. While seminars in provincial cities, such as Kiev and Vilnius, were squelched, those in Moscow and Leningrad had operated over a period of years with relatively little interference until recently. The Moscow Sunday Seminar, which had been blocked in the wake of Viktor Brailovsky's arrest in November, was able to resume regular Sunday sessions unmolested in early February. But this respite was short-lived; the authorities have shut it down three times since the end of April. On one Sunday during my visit at the end of May, the KGB barred the way to three different apartments making it impossible for a session to take place. Also in Moscow Alexander Lerner's seminar on mathematical biology, which recently held its 200th session, was blocked twice in April and May. In mid-May the seminars went into official recess for the summer. Our Soviet colleagues anxiously await the official reaction when they attempt to resume their

\section{An Irish question}

SIR - In your editorial of 25 June 1981

(p.601), you quite rightly in my view criticized the Science and Engineering Research Council (SERC) for turning down the proposal "that there should in future be an exchange of graduate students between the the United Kingdom and the Irish Republic on the modest scale of a dozen or so a year'. You may not be aware that the Department of Education (N. Ireland) awards postgraduate studentships to good graduates who have normally been resident in N. Ireland for at least 3 years immediately preceding the start of the proposed period of study. One type of research studentship, the so-called XNI award, is tenable at institutions in Great Britain or the Republic of Ireland or exceptionally, outside the British Isles. This arrangement, which I believe has existed for many years, meets the points you make about student exchange in respect of graduates from N. Ireland. Unfortunately, there is no reciprocal arrangment in the Irish Republic.

I have had several enquiries from final-year honours students reading biochemistry in the Republic who would like to have carried out postgraduate research in this department. The only suggestion I have been able to make is that the prospective research students should apply to Queen's University for a Visiting Studentship of which there are about two per annum for the whole world including Great Britain. Competition is very keen for these studentships and the prospects of success are small. Perhaps you should give the Ministry of Education in the Irish Republic a nudge in addition to the black mark which you awarded to SERC.

D.T. Elmore

Queen's University, Belfast, UK meetings in the fall.

Still another cause for concern is the use of academics as an instrument for persecution. Many scientists are now refused exit permits not because of allegations (usually unfounded) that they know state secrets, but simply because they are well educated. In fact the head of the administration department of the Communist Party's Central Committee bluntly told scientists that they are being detained "because you have degrees". At the same time the authorities are punishing scientists by abrogating their advanced degrees. Indeed three refusnik scientists told me their degrees had been revoked for "'unpatriotic behaviour,', that is, exercising their legal right in applying to emigrate.

While the situation of refusnik and dissident scientists has deteriorated alarmingly over the past year, this course is reversible. We can have an impact. Witness the return of Benjamin Levich, Mark Azbel, Valentin Turchin and others to productive scientific life due to the untiring efforts of Western scholars. We cannot afford to become hardened to the plight of oppressed colleagues who have much to contribute to a vital international science.

DOROTHY HiRSCH

Executive Director,

Committee of Concerned Scientists, New York, USA

\section{University cuts}

SIR - Union members have expressed particular concern over two aspects of the leading article "Change wanted"' (Nature 11 June, p.442).

(1) It seems to accept the principle of cutting back on funding of universities, an extraordinary position for a journal concerned with science and research.

(2) It does not answer the questions and propositions posed by Swinnerton-Dyer but suggests the necessary financial savings can be made by college managements acting in a managerial capacity and shedding staffs from all sections except academic.

With regard to this last point, there is no suggestion as to how teaching laboratories and research groups could maintain their standards or volume of work when numbers of technicians and other ancillary staff, already at a bare minimum in many institutes, are reduced even further.

You cannot fail to be aware that the whole question of Swinnerton-Dyer is currently the subject of intense discussion not only in the university but also between the University of London and the trade unions that represent all sections of staff. We feel that these discussions should continue in a serious way on the basis of the evidence submitted in the discussion documents and that they should not be prejudiced by statements such as yours that the "armies of ancillary staff"' should be chopped by the administrative action of the management of the schools.

M. OSMUNDSON

C. SCOTT

L. WAI.DOCK

Queen Elizabeth College branches of ASTMS, NALGO and NUPE, London, UK 